notable statues, groups and relief portraits grace many parks and public buildings throughout the United States and Canada, began work on the Franklin statue five years ago, and has described his own conception in the following words :

"A massive figure, tranquil in body, with latent power in his hands, but with an inquisitive expression in the movement of his head and the alertness of his eyes, ready to turn the full force of his keen mind on any problem that concerned life."

In a manner that would have aroused the keen interest of her famous ancestor, ten-year-old Miss Louisa Johnston Castle, of Wilmington, Delaware, a lineal descendant of Franklin, unveiled the statue by turning a searchlight upon a photo-electric cell.

In the three-day programme, Franklin was commemorated as "Patriot and Man", as "Philosopher and Educator", and as "Printer and Business Man". Special exhibits depicting the advance of science from Franklin's day to the present time, on display in the Wonderland of Science Museum, vied with lectures by noted men of science and educators of two continents in the tribute to the great American's scientific achievements. Developments in electricity were shown, from an electrical machine which Franklin once owned to a modern half-million volt surge generator producing man-made lightning. Progress in printing, 'Poor Richard's' own craft, was demonstrated from a hand-press used in Franklin's original printing shop to modern presses that print in four colours. Paper-making was performed by hand just as it was in Franklin's day, and the entire modern process from pulp to finished paper also was demonstrated on a miniature scale-model Fourdrinier paper-making machine. A replica of the "Pennsylvanian Fireplace", one of Franklin's outstanding inventions, was shown in contrast with an exhibition of the development within the last twenty years in automatic oil-heating equipment for home use.

In a notable series of lectures on pure science, given at the Franklin Institute on May 20, Sir James C. Irvine spoke on "Benjamin Franklin in Saint Andrews, 1759”, Dr. C. E. K. Mees, director of the Research Laboratory of the Eastman Kodak Company, Rochester, N. Y., who is a native of Wellingborough, England, and was educated at Harrogate and St. Dunstan's, on "Photography and the Advance of Pure Science"; Dr. Gilbert N. Lewis, dean of the College of Chemistry, University of California, Berkeley, Calif., on "Old and New Views of Acids"; Dr. George D. Birkoff, the distinguished mathematician of Harvard University, Cambridge, Mass., on "Electricity as a Fluid"; Dr. Forest Ray Moulton, permanent secretary of the American Association for the Advancement of Science, Washington, D.C., on "The Influence of Astronomy on Science"; Dr. Arthur L. Day, formerly director of the Geophysical Laboratory, Carnegie Institution, Washington, D.C., on "Volcanoes, Geysers and Hot Springs"; Dr. Louis Martin, director of the Pasteur Institute, Paris, on "L'Hospitalisation des Maladies Contagieuses" ; Dr. Thomas H. Morgan, of the California Institute of Technology, Pasadena, Calif., on "Human Heredity and Modern Genetics"; and Dr. Merritt L. Fernald, of Harvard University, on "Must All Rare Plants Suffer the Fate of Franklinia?"

Lectures on applied science were given at the Franklin Institute on the following day by Dr. Willis R. Whitney, vice-president in charge of research, General Electric Company, Schenectady, N.Y., who spoke on "It's Called Electricity"; Dr. Abel Wolman, professor of sanitary engineering, Johns Hopkins University, Baltimore, Md., on "The Trend of Civil Engineering since Benjamin Franklin"; and Dr. Harvey N. Davis, president of the Stevens Institute of Technology, Hoboken, N.J., on "Engineering and Health".

Delegates from leading learned societies and educational institutions of the United States and Europe were welcomed at the dedication ceremony by Philip C. Staples, president, and Dr. Henry Butler Allen, secretary and director of the Franklin Institute. Sir Albert Seward, delegate from the Royal Society of London, was in attendance with Lady Seward, and presented to the Institute a photostat copy of the certificate making Franklin a fellow of the Royal Society in $\mathbf{1 7 5 6 .}$

\title{
Artificial Production of Snow Crystals
}

$\mathrm{I}^{\mathrm{N}}$ NATURE of August 28, 1937, p. 345, an account was given by G. Seligman of experiments carried out at the University of Hokkaido by Prof. U. Nakaya. Since that article was written, Prof. Nakaya has made considerable progress towards his aim to produce, artificially and under strictly controllable conditions, the great variety of natural snow crystals*. He assumes that we can trace the entire history of the fallen snow crystal from observations of its size, form and habit, and infer the physical state of

* "Preliminary Experiments on the Artifleial Production of Snow Crystals". By Ukitirô Nakaya, Isonosuke Satô and Yatarô Sekido. "Further Experiments on the Artificial Production of Snow Crystals". Burther Experiments on the Artifial Production of Snow Crystals". Sci., Hokkaido Univ., Series II, Vol. II, No. 1; 1938.) 
its environment during condensation and during its subsequent movements through the atmosphere, if we can establish the laws governing its development.

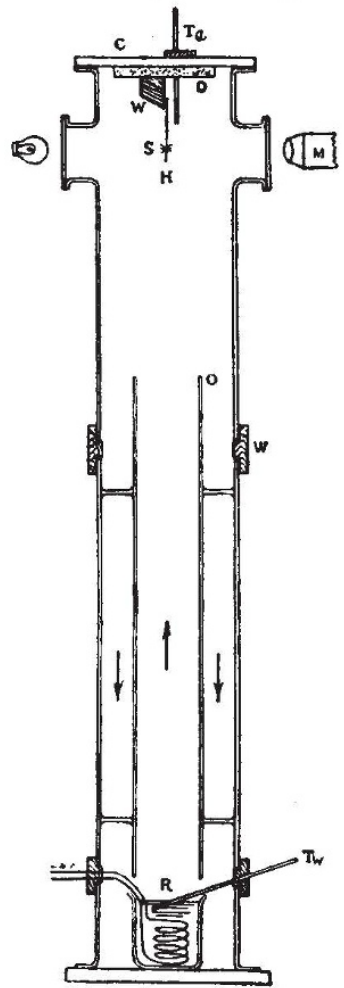

Fig. 1.

Apparatus for the artificial PRODUCTION OF SNOW CRYSTALS.

Nakaya's experiments were carried out in a cold chamber the temperature of which could be lowered to $-50^{\circ}$. The apparatus employed for the production of artificial snow crystals is shown in Fig. 1. By heating the water in the dish $R$ with an electric coil, a flow of saturated, warm air is produced in the inner of two concentric cylinders. When the air reaches the point $O$ it is chilled by the walls of the cooled outer cylinder. The rabbit hair $H$ serves as a nucleus for the condensation of the now supersaturated vapour and the growing crystal $S$ can be observed through the telescope $M$. The temperature at the water surface $\left(T_{w}\right)$ and that near the crystal $\left(T_{a}\right)$ are recorded. The apparatus has the advantages that both the temperature and the degree of supersaturation can be varied within wide limits, and that a nucleus for the condensation is provided which allows unhampered growth of the crystal in all directions and yet keeps it stationary in front of the telescope. Fig. $2 a$ shows a snow crystal grown in this apparatus, still attached to the rabbit hair. It is seen from comparison with the natural snow crystals reproduced in Fig. $2 b$ that the artificial product resembles the natural one in regularity as well as in degree of complexity.
Nakaya divides the growth of the snow crystal into two stages: the formation of the germ and its subsequent development. $\mathrm{He}$ finds that the type of the former greatly influences the final shape of the crystal, however radically he alters $T_{w}$ and $T_{a}$ during the second stage. Therefore, the first object of his investigations was an enumeration of possible types of germs and a study of the conditions for their formation. Schematic drawings of his twelve types of early stage snow crystals are shown in Fig. 3, and a record of their history is given in the table which follows. Evidently temperatures above $-20^{\circ} \mathrm{C}$., with a relatively copious supply of water vapour, produce complex shapes such as dendrites or "assemblages of sectors", the latter probably caused by multiple twinning. The formation of simpler types appears to be favoured by lower temperatures, while the perfection of the crystals seems to depend primarily on the regularity of the temperature gradient. Rapid chilling of highly supersaturated vapour produces clusters of irregular fragments (Type 2) or even frozen droplets.

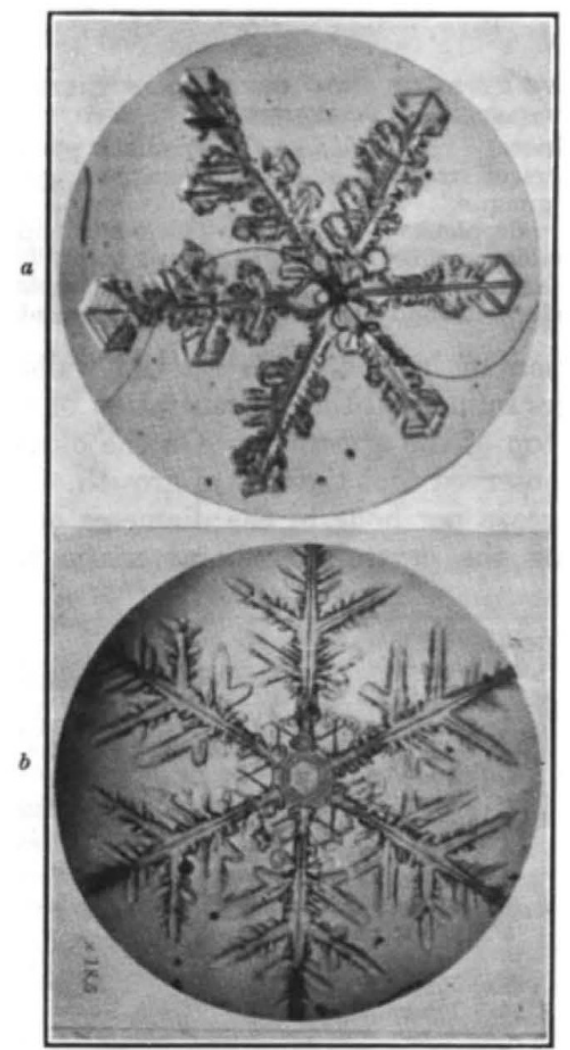

Fig. 2.

Snow crystals. (a) Artiftcial crystat. $\times$ approx.

11. (b) Natural CRYSTAL. XaPPROX. 12.

The actual degree of supersaturation in the neighbourhood of the rabbit hair was not measured in any of Nakaya's experiments, but a 
supersaturation ratio $(s)$ is given, defined as the ratio of the saturation vapour pressure at the water surface $\left(T_{w}\right)$ to that near the crystal $\left(T_{a}\right)$. It was found, however, that experiments with identical supersaturation ratio did not always produce the same results, since uncontrollable factors such as
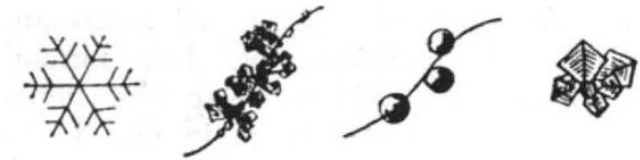

1
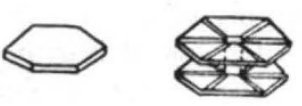

6
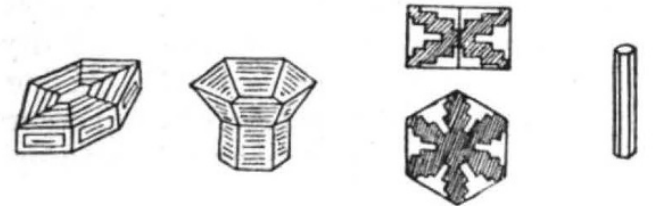

10

Fig. 3.

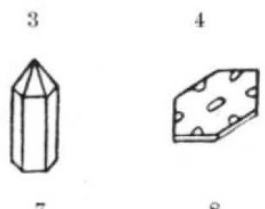

12

TWELVE TYPES OF SNOW CRYSTALS IN THEIR EARLY STAGES :

1. Dendrite.

2. Clusters of irregular fragments.

3. Frozen droplets.

4. Assemblages of sectors.

5. Thin hexagonal plate.

6. Cylinder with end plates.

7. Prismatic pyramid.

8. Hexagonal plate with design.

9. Thick hexagonal plate.

10. Cup crystal.

11. Prismatic skeleton.

deposition of hoar crystals on the walls of the cylinders influenced the concentration of moisture at the top of the apparatus. On the other hand, it was observed that the rate of growth, defined as the increase per hour in the diameter of a circle enclosing the crystal, is characteristic for each
During the second stage of crystal development, the rates of growth have been measured with considerable accuracy. Some of the results are given below :

Fern-like dendritic branches of great complexity More massive hexagonal plates with broad extensions at the corners Hexagonal plates and assemblages of sectors of Massive prisms, pyramids, prismatic needles* and

"spirals" • * In his article in NATURe, Mr. Seligman expressed his surprise that Nakaya observed needles and prisms at different ends of the temperature scale in snowfalls, the needles occurring under warm and the prisms under extremely cold conditions. It may be suggested that these needles are not prismatic, but consist of branches of dendrites which have broken off from their base and lost the details of their structure by melting.

The spirals are a peculiar phenomenon which has been observed in crevasse hoar by Seligman and others. They look like ordinary hexagonal prisms, but on closer inspection their cross-section perpendicular to the hexagonal axis is seen to resemble a 'hexagonal clock-spring'. Slow growth of the germ is essential for this type. In Nature, it develops only under calm conditions with a small temperature gradient providing for a slow rate of sublimation.

Nakaya also reports that rhombohedral ( $\beta$-ice) and cubic ice crystals were produced at temperatures of about $-30^{\circ} \mathrm{C}$. and low saturations. In view of the fact that neither $\mathrm{X}$-rays nor polarized light were employed for their identification, these results must be regarded as rather uncertain. Finally, snow crystals were grown from heavy water. It is interesting to note that their external structure was very similar to that of snow crystals grown from ordinary water.

Nakaya has taken many thousands of photomicrographs of artificial snow crystals. By his elaborate researches he has created an invaluable new implement for the meteorologist and provided the research worker on snow with a most interesting collection of new facts. It is to be hoped that by

\begin{tabular}{|c|c|c|c|c|c|c|c|c|}
\hline \multirow{2}{*}{$\begin{array}{l}\text { Type } \\
\text { No. }\end{array}$} & \multirow{2}{*}{ Type } & \multicolumn{3}{|c|}{$T_{w}$} & \multicolumn{3}{|c|}{$T_{a}^{\prime}$} & \multirow{2}{*}{ (in hours) } \\
\hline & & Initial & Middle & Final & Initial & Middle & Final & \\
\hline 1 & Small dendrite & $+5^{\circ} \mathrm{C}$ & $+10^{\circ} \mathrm{C}$ & $+15^{\circ} \mathrm{C}$. & $-19^{\circ} \mathrm{C}$. & $-17^{\circ} \mathrm{C}$ & $-18^{\circ} \mathrm{C}$ & 0.5 \\
\hline 2 & Clusters of irregular fragments & +3 & +35 & +20 & -20 & -13 & -15 & 0.5 \\
\hline 3 & Frozen droplets & +6 & +46 & +25 & -22 & -10 & -12 & 0.5 \\
\hline 4 & Assemblages of sectors & +10 & +16 & +19 & -15 & -13 & -12 & $1 \cdot 5$ \\
\hline 5 & Thin hexagonal plate & +6 & +10 & $\div 12$ & -24 & -22 & -16 & 2 \\
\hline 6 & Cylinder with end plates & 0 & +8 & +20 & -20 & -20 & -14 & $5 \cdot 5$ \\
\hline 7 & Prismatic pyramid & +3 & +5 & +10 & -29 & -27 & -25 & 7 \\
\hline 8 & Hexagonal plate with design & +4 & $+4 \cdot 5$ & $+4 \cdot 5$ & -26 & -27 & -28 & 15 \\
\hline $\mathbf{9}$ & Thick hexagonal plate & +2 & +4 & +1 & -38 & -36 & -39 & 18 \\
\hline 10 & Cup crystal & +5 & +4.5 & +4 & -21 & -21 & -19 & 17 \\
\hline 11 & Prismatic skeleton & +6 & +8 & +10 & -22 & -22 & -20 & 20 \\
\hline 12 & Prismatic needle & +4 & +4 & +4 & -30 & -30 & -28 & 25 \\
\hline
\end{tabular}

type and can serve as a qualitative measure of the degree of supersaturation. However, absolute measurements of the supersaturation values in terms of water content per unit volume seem highly desirable in view of the possible applications of Nakaya's researches to meteorology. a more systematic presentation of his results, by improvement of his nomenclature along more accepted crystallographic lines and by quantitative measurement of his supersaturation values, he will justify the expectations of those who have followed his earlier work.
Max Perutz. 